\title{
O PROBLEMA DA PARTICIPAÇÃO POLÍTICA NO MODELO DELIBERATIVO DE DEMOCRACIA
}

\author{
Francisco Paulo Jamil Almeida Marques
}

\begin{abstract}
RESUMO
O trabalho discute as premissas do modelo deliberativo de democracia que lidam com a questão da participação política, no intuito de esclarecer no que consiste a participação de acordo com os parâmetros discursivos. A partir da revisão de uma parcela importante da literatura contemporânea em Teoria Democrática, e sem perder de vista as sistematizações anteriores em Teoria Política, são apontadas três condições fundamentais para engendrar-se a participação de acordo com o modelo deliberativo: (a) as instituições políticas devem criar e oferecer aos cidadãos oportunidades de input de razões públicas; $(b)$ faz-se necessária uma melhora nas condições sócio-econômicas dos indivíduos; (c) é preciso dar atenção a determinados princípios que atuam na regulação das interações e dos argumentos que se encontram em debate. Em seguida, reflete-se acerca das críticas e das falhas apontadas pelos opositores do deliberacionismo. Ao final do texto, realiza-se um apanhado acerca dos limites e dos méritos do modelo em tela quanto à discussão do problema da participação nas democracias contemporâneas.
\end{abstract}

PALAVRAS-CHAVE: democracia; participação política; deliberação pública; discurso; representação.

\section{INTRODUÇÃO ${ }^{1}$}

Pode-se dizer que a vertente deliberativa da teoria democrática teve origem, dentre outras contribuições, na confluência de alguns dos princípios encontrados nos trabalhos mais recentes de John Rawls (1996) e de Jürgen Habermas (1997). Enquanto o filósofo norteamericano propunha uma reforma do liberalismo, sem deixar de reconhecer a primazia dos direitos e das liberdades individuais, Habermas partia da idéia de um rearranjo das premissas da democracia radical, mesmo sem abrir mão, por exemplo, da necessidade de promover-se uma influência mais acentuada da esfera civil no que concerne à condução dos negócios públicos.

Ainda que não se possa subsumir a polêmica intelectual travada por esses dois pensadores em um único tema, há razão em afirmar-se que, no

\footnotetext{
1 O autor agradece às considerações e críticas dos pareceristas anônimos do texto ora apresentado, que colaboraram de modo fundamental para incrementar o argumento do texto. A Coordenação de Aperfeiçoamento de Pessoal de Nível Superior (Capes) e o Conselho Nacional de Desenvolvimento Científico e Tecnológico (CNPq) apoiaram, por meio de bolsa e de financiamento, a pesquisa que originou este trabalho.
}

final das contas, é especificamente quanto ao grau desejável de influência da esfera da cidadania no processo de produção da decisão política sobre o que divergem os autores. Na perspectiva de Rawls, a Suprema Corte, no caso dos Estados Unidos (EUA), seria o ambiente por excelência a abrigar a deliberação pública, o que implica alcance limitado dos agentes envolvidos no processo discursivo. Por outro lado, a maioria dos autores deliberacionistas, inclusive Habermas, considera essencial uma maior participação dos cidadãos quando da produção da decisão política. É nesse ponto em que se pode enxergar uma feição mais "forte" de democracia defendida por uma parcela dos estudiosos ligados à deliberação ${ }^{2}$.

Por trás da idéia dos investigadores vinculados à tendência discursiva de que a participação deve

\footnotetext{
2 Um primeiro ramo da teoria deliberativa, com uma projeção mais reformista do liberalismo, inspirada em Rawls, é sustentado por autores como Joshua Cohen (1996) e Amy Gutmann e Dennis Thompson (1996; 2004). Outra subvertente, influenciada por Habermas e desenvolvida por filósofos como John Dryzek (1994; 2004), Seyla Benhabib (1996) e James Bohman (1996), preserva a necessidade de que haja alguma mudança de caráter mais incisivo no arranjo democrático para conferir maior legitimidade a esse regime de governo.
} 
ser alargada, encontra-se um motivo elementar: se a democracia deliberativa tem como uma de suas metas a busca por mecanismos de fortalecimento da legitimação do processo de produção da decisão política, nada mais natural que argumentar a favor do envolvimento dos cidadãos nas esferas discursivas que lidam com a res publica ${ }^{3}$. Nas palavras de John Dryzek: “[...] os resultados [as decisões políticas obtidas a partir das deliberações] são legítimos na medida em que recebam o assentimento refletido por meio da participação em uma deliberação autêntica da parte de todos aqueles sujeitos à decisão em questão" (DRYZEK, 2004, p. 41-42).

É preciso, entretanto, esclarecer no que consiste a participação política de acordo com os moldes deliberacionistas, bem como reconhecer as críticas mais candentes a essa concepção. Este é o problema do presente artigo.

Sabe-se que o modelo deliberativo argumenta em favor da intromissão da esfera civil nas práticas democráticas não apenas por meio daqueles procedimentos característicos da agregação das disposições eleitorais (método de participação considerado suficiente por determinadas tradições em teoria democrática, como o elitismo competitivo de Schumpeter (1942)), mas, também, a partir de contribuições substantivas, guiadas por princípios pré-estabelecidos. É justamente graças a essa concepção disposta a complementar o que dizem perspectivas democráticas tradicionais que Marcos Nobre (2004) afirma ser a democracia deliberativa o modelo que institucionaliza o ideal de exercício coletivo do poder político.

Ao encerrar um conjunto de proposições direcionadas a fomentar aquilo que considera adequado do ponto de vista do funcionamento e da efetividade dos regimes democráticos, o

\footnotetext{
3 A discussão sobre a idéia de participação política mostrase uma das mais candentes na teoria política contemporânea. Sem perder de vista a profusão de investimentos epistêmicos relacionados à idéia de participação, nem as distintas dimensões que cercam um conceito tão polêmico (tratado com maior profundidade em Held (1987), Cohen e Arato (1992), Bobbio (2000), Marques (2008), entre outros), quando este trabalho referese à participação política ele lida especificamente com aquelas oportunidades de intervenção no jogo político auferidas aos cidadãos por parte das instituições do Estado.
}

deliberacionismo destaca três pontos fundamentais para refletirmos acerca da interface entre, de um lado, a participação da esfera civil e, de outro, a montagem institucional que rege a atividade cotidiana das democracias.

O primeiro ponto tem a ver com o diagnóstico a apontar uma insuficiência ou carência de mecanismos institucionais de participação aptos a permitirem que os cidadãos possam, a partir de parâmetros deliberativos, manifestarem-se, considerar as razões dos outros, ter suas razões examinadas e, por fim, tomar parte nas decisões. Estudiosos a exemplo de Bernard Manin (1997) consideram que, na configuração das democracias modernas, não foi previsto um espaço maior de intervenção para o povo reunido em assembléia na produção da decisão política. Assim, os autores deliberacionistas defendem a necessidade de uma maior permeabilidade das instituições e das estruturas do Estado que estão sob tutela administrativa transitória dos representantes eleitos (BOHMAN, 1996; 1998; FUNG, 2005; DRYZEK, 2007; WARREN, 2007).

Em segundo lugar, as possibilidades para a participação, no modelo deliberativo, não se referem apenas ao caráter das ferramentas institucionais de input oferecidas, mas, também, às condições minimamente aceitáveis (sobretudo aquelas de cunho sócio-econômico) das quais devem usufruir agentes e cidadãos envolvidos no processo político (YOUNG, 2000).

A terceira questão refere-se aos trâmites internos dessa participação, isto é, aos princípios que regulam e submetem tal participação a determinados constrangimentos procedimentais e substantivos. Para além dos princípios de reciprocidade, publicidade e accountability mencionados por Amy Gutmann e Dennis Thompson (1996; 2004) (e explorados, em diferentes medidas, por Bohman (1996) e Arato (2002)), é necessário explicar em que termos os deliberacionistas defendem uma perspectiva de cooperação mútua tanto durante quanto depois do processo de produção da decisão política.

Acredita-se que cada uma dessas questões mereça uma avaliação e exposição mais apuradas, uma vez que poucos trabalhos na área de deliberação pública dedicam-se a realizar tal empreendimento de maneira conjunta (MUTZ, 2006). As páginas seguintes esforçam-se, assim, para esclarecer os pressupostos deliberativos 
quanto à participação civil e apontar as principais dificuldades encontradas pelos críticos no que se refere à promoção da participação nos moldes da teoria discursiva.

\section{A DEMOCRACIA DELIBERATIVA E A PRO- MOÇÃO DE MECANISMOS INSTITUCIO- NAIS FAVORÁVEIS À PARTICIPAÇÃO}

Estudiosos, a exemplo, de Carole Pateman (1992), James Bohman (1996), Bernard Manin (1997), Jon Elster (1998), Benjamin Barber (2004), entre outros, por ressaltarem a importância de idéia de soberania popular para afirmar-se a consistência do regime democrático, consideram inadequada a corrente divisão do trabalho político entre esfera dos representantes e esfera civil.

É verdade que não se pode confundir, de um lado, os estudiosos vinculados às teorias da democracia participativa com, de outro lado, os autores a demonstrarem predileção pelas premissas deliberativas. Não obstante a proximidade entre as duas abordagens (afinal, os deliberacionistas defendem a criação de oportunidades de participação e reformulam determinados ideais republicanos), elas acabam deixando clara uma tensão refletida, dentre outros aspectos, no padrão considerado desejável de intervenção política da esfera civil, conforme será destacado logo à frente. Barber (2004) e sua "strong democracy", por exemplo, operam em favor de formas mais diretas de intervenção política em diversas instâncias do Estado, o que nem sempre é visto com bons olhos mesmo por autores discursivos influenciados pela teoria crítica, como Bohman ${ }^{4}$.

A convergência argumentativa dos autores dessas duas linhagens, no entanto, dá-se na constatação de que, ao longo do processo que deu origem à montagem institucional das democracias liberais modernas, a esfera civil não foi prevista no arranjo da administração do Estado como ente decisório ou com influência destacada

\footnotetext{
4 De acordo com James Bohman: "Nos aperfeiçoamentos delineados ao longo da última década, os proponentes da democracia deliberativa têm se distanciado das concepções participativas de democracia e de bem comum e se inclinado em direção às instituições, as quais eles originalmente rejeitaram enquanto ambientes de raciocínio público" (BOHMAN, 1998, p. 400). Todas as citações de trechos de trabalhos publicados originalmente em inglês foram traduzidas pelo autor deste texto.
}

no processo de discussão dos negócios públicos. O modelo democrático de viés liberal acabou privilegiando, de modo a excluir outras modalidades mais fortes de participação, a capacidade dos cidadãos de, na posse de liberdades e direitos individuais, deputar mandatos em intervalos pré-estabelecidos ${ }^{5}$.

É a partir do contraponto a essa disposição liberal que a democracia deliberativa busca uma saída com vistas a recuperar, pelo menos parcialmente, a consistência da idéia de soberania popular e assegurar à esfera civil um lugar de maior destaque na divisão do trabalho político. Tal empreendimento coaduna-se com a necessidade, defendida por certos teóricos do modelo discursivo, de realização de modificações institucionais na configuração dos estados democráticos (BOHMAN, 1996; 1998; COHEN \& SABEL, 1997; FUNG \& WRIGHT, 2001; STEINER, BÄCHTIGER \& SPÖRNDLI, 2001; CHAMBERS, 2003; WAMPLER \& AVRITZER, 2004; FUNG, 2005; WARREN, 2007; AVRITZER, 2009).

Amy Gutmann e Dennis Thompson (1996), por exemplo, defendem que as instituições do Estado têm a responsabilidade precípua de promover a deliberação pública, não se admitindo a existência de instâncias em que razão, por um lado, e poder político, por outro, convivam separadamente. Para tais estudiosos, o funcionamento dos poderes Executivo e Legislativo (onde estão concentradas as capacidades de aprovar normas e efetivar as decisões) costumeiramente não obedece a princípios de oferecimento de razões e justificativas públicas a envolverem os cidadãos, o que é um problema a ser consertado.

Além da carência de oportunidades institucionais, os pensadores do modelo discursivo procuram lidar, também, com problemas atinentes à apatia e ao cinismo político dos da esfera civil (BENNETT, 1986; ELIASOPH, 1998; MUHLBERGER, 2001; DRYZEK, 2007). O deliberacionismo defende, assim, que a ênfase dessas modificações e reformas institucionais, bem como a natureza dos mecanismos participativos por elas sugeridos, seja pensada de

\footnotetext{
5 Não se pode perder de vista, a esse ponto, a contribuição clássica de Benjamin Constant (1985) acerca das diferenças entre a democracia dos antigos e dos modernos.
} 
modo a satisfazer padrões de engajamento que dêem a entender aos cidadãos que suas contribuições serão efetivamente levadas em conta (consolidando-se o sentimento de eficácia política já estudado por Almond e Verba (1963), Verba, Schlozman e Brady (1995), Abers (2000), Delli Carpini (2000) e Coelho (2007)).

Expostas, em linhas gerais, as dificuldades encontradas no plano institucional relativas à implementação de padrões deliberativos de participação da esfera civil, a questão pendente refere-se à dinâmica prática que deve guiar a configuração (ou desenho, como preferem Warren (2007), Avritzer (2008) e Dryzek e Niemeyer (2008)) de mecanismos participativos. Isto é, deve-se prover uma noção do que os autores deliberativos consideram adequado quanto ao desenho de ferramentas a serem empregadas pelos cidadãos no intuito de exercer maior influência sobre o sistema político.

Deliberacionistas como James Fishkin (1991; 2002), Bohman (1996), Gutmann e Thompson (1996; 2004) e John Gastil (2000) intercedem, mais cuidadosamente, pela análise criteriosa dos mecanismos de participação a serem oferecidos aos cidadãos, uma vez que nem toda forma de intervenção política pode ser considerada apta para preencher os requisitos deliberativos. James Bohman cita o caso de referendos como instrumentos de democracia direta que têm lugar em determinadas localidades do estado da Califórnia, Estados Unidos. Sem a devida orientação e formatação de um processo informativo e de debate público, tais referendos podem mais prejudicar do que contribuir com os regimes democráticos. Para o autor: "[...] tais referendos são, muitas vezes, mais apelos à discriminação popular e à alienação política do que uma deliberação ampla da comunidade. Por causa da facilidade em propô-los, os referendos são tão episódicos e não reflexivos quanto as atuais sondagens de opinião" (BOHMAN, 1996, p. 245).

Entre as ferramentas que atendem aos parâmetros deliberativos, Bohman cita o emprego de "balanços de impactos públicos", elaborados por parte das instituições do Estado e de seus agentes, cuja função seria expor de que forma as razões apontadas pelos cidadãos foram consideradas para a formatação de uma decisão (idem, p. 190). Gastil, por sua vez, sugere a criação de painéis deliberativos (citizen panels), cuja dinâmica favorece a existência de um ambiente cooperativo e público de avaliação de razões e argumentos plurais, sobretudo a partir do provimento antecipado de informações de qualidade (GASTIL, 2000, p. 137). Outro mecanismo promovido pelos autores do modelo aqui em questão com o objetivo de colher contribuições da esfera civil são as pesquisas deliberativas de opinião pública. De acordo com James Fishkin (1991; 2002), essas pesquisas atuam de modo a selecionar uma amostra aleatória de cidadãos e a estimular a discussão entre eles após um processo informativo.

Em suma, pelo que se pôde perceber, o modelo deliberativo privilegia um tipo específico de participação pública (e não aquela que ocorre de maneira isolada, com a qual se mostra satisfeito o liberal-elitismo de Schumpeter (1942)), que leve em consideração as diferentes razões erigidas por integrantes da esfera civil e da esfera política institucional.

\section{II.1. Representação e teoria deliberativa}

Nesse contexto de busca por maior abertura das instituições do Estado às contribuições da esfera civil, é importante, todavia, deixar claro que os autores deliberativos não acenam reivindicando formas mais diretas de democracia, proposta típica, como se mencionou anteriormente, de estudiosos tradicionais cujo argumento também se volta ao fortalecimento da participação(ARNSTEIN, 1969; BARBER, 2004).

Obviamente, seria um erro ignorar as próprias diferenças internas aos autores deliberacionistas (e aqui não se está referindo, necessariamente, àquelas linhas gerais de inspiração rawlsiana ou habermasiana a marcarem o debate interno ao modelo), mas o fato é que, não obstante tais divergências (SILVA, 2004), os investigadores vinculados a essa corrente de pensamento (sejam os cientistas políticos, sejam os filósofos) reconhecem a necessidade da representação ${ }^{6}$ para que o sistema político continue a funcionar sem deixar de lado a eficiência (reivindicação de cunho

6 A intenção, aqui, não é conferir um tratamento aprofundado ao conceito de representação política em suas mais diferentes faces, mas, apenas, oferecer um panorama sobre as considerações feitas por parte dos autores deliberativos no que concerne à interface entre participação e representação política. Ou seja, pretende-se enfatizar a diferença entre autores participacionistas e 
liberal, tratada com maior profundidade originalmente em Max Weber (1946)).

Ressalte-se, ainda, a cautela atinente às demandas excessivas de tempo e engajamento que poderiam ser impostas aos cidadãos em contextos de deliberação pública recorrente (BURKHALTER, GASTIL \& KELSHAW, 2002; DRYZEK, 2004). Isso não significa, porém, que uma maior capacidade da esfera civil em atuar, sugerir, interferir, perquirir e cobrar justificativas de seus representantes públicos deixe de ser uma meta plausível. Nas palavras de Bohman: "Em instituições que operam através de processos em larga escala espacial e temporal [...] é mais importante fazer uma divisão do trabalho mais democrática do que aboli-la em nome da maximização da participação direta dos cidadãos" (BOHMAN, 1996, p. 242).

Assim sendo, mesmo considerando a relação de causa e conseqüência entre o artifício da representação e a restrição das oportunidades participativas dos cidadãos, os teóricos deliberativos não estão dispostos a abrir mão de tal mecanismo, uma vez que ele garante, por exemplo, que visões desrespeitosas ou ilegítimas aos direitos e liberdades das minorias possuam atuação e conseqüência limitadas ${ }^{7}$ (BENHABIB, 1996; BOHMAN, 1996; COHEN, 1996; YOUNG,

deliberacionistas por meio da compreensão distinta que eles tendem a apresentar quanto às práticas representativas da democracia. Para um exame mais detalhado da idéia de representação, indica-se obras de autores como Pitkin (1987), Manin (1997) e Urbinat (2006). Já especificamente quanto à relação entre representação e teoria deliberativa, consulte-se Vitale (2007).

7 Outra autora deliberacionista, Iris Marion Young, sustenta a idéia de que a representação é necessária ao criticar os autores democratas radicais. "Democratas radicais freqüentemente desconfiam das instituições de representação política. [...] A representação, eles sugerem, 'aliena a vontade política ao custo do genuíno autogoverno', 'debilita a habilidade da comunidade em funcionar como um instrumento regulador da justiça' e 'impede a evolução de um público participante no qual a idéia de justiça pode criar raízes'. [...] A posição antirepresentativa [...] se recusa a encarar as realidades complexas do processo democrático, e, de forma errônea, opõe representação à participação. A representação é necessária porque a rede da vida social moderna muitas vezes liga a ação de algumas pessoas e instituições em um lugar com conseqüências em muitos outros lugares e instituições" (YOUNG, 2000, p. 124).
2000). Chega-se, então, ao argumento de que não há como abrir mão da representação política, mas que a realização de tal artifício precisa dar-se de modo a contemplar certos parâmetros. De acordo com Gutmann e Thompson: "Mais participação na política é, em geral, algo desejável [...] mas a representação, de alguma forma, está aqui para ficar. Pelo menos para o futuro próximo, a escala e a complexidade do governo moderno, incluindo qualquer tipo de democracia, requer uma medida significante de representação. [...] A democracia deliberativa não especifica uma única forma de representação. Ela procura por modos de representação que apóiem a troca de argumentos sérios e moralmente sustentáveis no interior dos corpos legislativos, entre legisladores e cidadãos e entre os próprios cidadãos" (GUTMANN \& THOMPSON, 1996, p. 130-132).

A concepção desses autores é montada na intenção de fazer com que os representantes atuem de modo mais aberto quando da formulação das decisões, mas que possam, ao mesmo tempo, resistir à pressão da tirania da maioria de modo justificado. Dessa forma, a proposta de democracia deliberativa esforça-se em encontrar um caminho que, além de não comprometer o bom funcionamento e a estabilidade do sistema político, não exija dos cidadãos um engajamento ativo e constante - isto é, um engajamento que não demande uma participação em tempo integral e de modo dedicado. Essa linha tênue entre requerer uma maior participação civil do que aquela prevista pelos modelos agregativos ao mesmo tempo em que se procura impor limites a tal participação mostra-se compatível com aquelas idéias que marcam os primórdios da vertente deliberativa, relativas à reforma do liberalismo e às tentativas de contenção dos ideais dos democratas radicais.

\section{DAS CONDIÇÕES QUE DEVEM REGER A PARTICIPAÇÃO DOS CIDADÃOS NO MO- DELO DELIBERATIVO DE DEMOCRACIA}

Enquanto os teóricos identificados com o modelo participativo(PATEMAN, 1992; BARBER, 2004) procuravam estabelecer os fundamentos de sua concepção no tão somente oferecimento de oportunidades de interferência no processo de produção da decisão política (com fins pedagógicos, sobretudo), a impressão que se tem é que, no modelo deliberativo, tal participação é vista como algo natural. Isto é, não se faz necessária, para a concepção discursiva, uma 
defesa tão enfática e contínua da participação dos cidadãos, a ponto de tal aspecto caracterizar a reivindicação por excelência da tradição. É nesses termos que, partindo-se dos pressupostos da democracia deliberativa, abre-se espaço para discutir não simplesmente a importância da participação (seu status é reconhecido a priori), mas para esclarecer-se, paralelamente, em que parâmetros, e por meio de quais instrumentos, deve-se dar tal interferência.

Um dos pontos mais ressaltados na concepção deliberativa refere-se à necessidade de aperfeiçoamento das condições sociais dos cidadãos de modo a fortalecer-se o uso da razão pública. Isso porque os cidadãos não podem ser considerados iguais quanto à possibilidade de reivindicar demandas e apresentar razões se enfrentam dificuldades, por exemplo, para sobreviver com dignidade mínima (CONOVER, SEARING \& CREWE, 2002; DUTWIN, 2003; DRYZEK \& NIEMEYER, 2008).

James Bohman (1996) argumenta, por exemplo, que uma deliberação pública que não atente para as desigualdades sociais que definem o papel dos atores ao longo do processo político será, necessariamente, falha. Para Bohman, é exatamente a habilidade para se iniciarem atos deliberativos o que representa um patamar mínimo de diagnóstico de igualdade política ${ }^{8}$. Assim, se há agentes que sequer conseguem fazer-se ouvir ou que não possuem as mínimas condições de iniciar uma contenda, pode-se questionar a legitimidade da decisão.

A questão, em outras palavras, é: como podem os mais pobres demandar melhores condições de vida e um estado de bem-estar que garanta, minimamente, um ambiente mais propício à participação política se não têm condições de iniciarem contendas reivindicatórias por si mesmos? Nesse mesmo sentido, Álvaro de Vita (2004) defende a articulação de "reformas institucionais e políticas públicas adequadas, para proteger os interesses e elevar a voz dos mais vulneráveis" (idem, p. 119).

\footnotetext{
8 Ao analisar espaços deliberativos que contam com o envolvimento de cidadãos, Vera Schattan Coelho reforça a perspectiva de que, caso não sejam apontados mecanismos para aliviarem-se determinados tipos de desigualdades, a qualidade da participação estará comprometida (COELHO, 2007, p. 79).
}

Gutmann e Thompson (1996), por sua vez, admitem a mesma dificuldade quanto às condições de atuação política dos cidadãos mais desfavorecidos. Os indivíduos de alcance sócioeconômico limitado são os menos propensos a tomarem parte na condução dos negócios públicos, tanto por serem acometidos por preocupações de outras naturezas (a exemplo da própria sobrevivência financeira), quanto por, tendencialmente, contarem com capacidades diminutas de influência junto a representantes políticos.

Em suma, os deliberacionistas afirmam que uma pluralidade efetiva de argumentos ou uma verdadeira "constelação de discursos" (DRYZEK, 2004) apenas pode ganhar sustentação em um ambiente que favoreça a intervenção nos negócios públicos de cidadãos originários de diferentes realidades sociais. Daí a necessidade de promoverem-se melhorias no bem-estar com vistas a aperfeiçoar a participação e a qualidade das deliberações públicas ${ }^{9}$.

\section{DOS TRÂMITES INTERNOS REFEREN- TES À PARTICIPAÇÃO DOS CIDADÃOS NA DELIBERAÇÃO PÚBLICA}

De acordo com Amy Gutmann e Dennis Thompson (1996; 2004), três princípios regulam a operação das intervenções e das interações políticas quando do processo de discussão de temas de natureza pública, conformando, assim, um conjunto a orientar as condições sob as quais, idealmente, ocorre a participação deliberativa: reciprocidade, publicidade e accountability.

Especificamente acerca da interferência política da esfera civil, a premissa básica da reciprocidade é que os cidadãos devem demonstrar respeito uns pelos outros no que concerne ao trato pessoal e às posições defendidas em fóruns públicos. Tal patamar de respeito mútuo garante que, na pior das hipóteses, obtenha-se uma discordância civilizada entre as opiniões diversas e, ademais, que os agentes em confronto possuam disposição de colocar-se no lugar do

\footnotetext{
9 É importante notar, em tal cenário, a reverberação que vem ganhando o debate entre Nancy Fraser e Axel Honneth (2003), dentre outros investigadores, sobre as noções de reconhecimento e redistribuição.
} 
outro para avaliar se sua proposta não atinge seus oponentes de maneira injusta. O ideal traçado por Gutmann e Thompson, assim, é que os cidadãos, ao pensarem para além de suas necessidades individuais, voltem a cogitar aquilo que havia sido posto em segundo plano pelas teorias da escolha social e racional, isto é, a noção de bem comum, construído coletivamente. Para Gutmann e Thompson: "Agregar o que os cidadãos querem individualmente, aquilo que a análise política utilitarista faz melhor, não necessariamente produz o mesmo resultado do que pedir aos cidadãos para que considerem juntos o que eles querem coletivamente" (GUTMANN \& THOMPSON, 1996, p. 174).

A conseqüência da reciprocidade para a participação dos cidadãos reflete-se, em suma, na exigência de padrões mínimos de civilidade cujo intento seja dar ouvidos a argumentos que, em um primeiro instante, podem mostrar-se nocivos àquilo que determinados cidadãos têm em mente ou à sua convivência cotidiana.

Já o princípio da publicidade (idem; GUTMANN \& THOMPSON, 2004) demanda, primordialmente, a observação do caráter público das razões que os representantes e os cidadãos oferecem para justificar ações políticas. Dessa forma, razões formuladas no sentido de favorecer determinado indivíduo, grupo ou, o que é pior, orientadas a prejudicar injustamente outros agentes, por exemplo, não preencheriam os requisitos do princípio da publicidade. Uma das inspirações para se fundamentar tal princípio, enfatize-se, pode ser encontrada em Kant, no seu Ensaio à Paz Perpétua.

O último princípio, o da responsabilização (ou accountability), é compreendido de maneira mais comum como o constrangimento imposto aos representantes públicos em relação à prestação de contas de suas ações e propostas, configurando um processo de troca e abertura para o aperfeiçoamento (ou mesmo revisão, caso o futuro assim prove necessário) das razões (GUTMANN \& THOMPSON, 1996; 2004; ARATO, 2002). Saliente-se, todavia, que a idéia de accountability, na perspectiva da participação deliberativa, envolve, também, a prestação de contas atinente às razões oferecidas por outros agentes envolvidos no processo de discussão dos negócios públicos. Isto é, os próprios cidadãos estão sujeitos a tal princípio ao apresentarem-se para tomar parte em contendas políticas ${ }^{10}$.

A meta final dos deliberacionistas ao defender esses três princípios é, na verdade, aperfeiçoar o processo de elaboração de razões e justificativas com vistas a alcançar-se um entendimento entre aqueles que tomam parte no debate público. De acordo com os autores arrolados até aqui, uma discussão na qual os agentes envolvidos portamse de maneira a contemplar, em suas formulações, elementos concernentes às idéias de reciprocidade, publicidade e accountability, tende a estabelecer os termos adequados para uma cooperação contínua (CHAMBERS, 2003). Isso quer dizer que o estabelecimento de princípios substantivos e procedimentais típicos da proposta deliberativa coaduna-se não apenas com a busca de legitimação e justificação das decisões originadas no processo de deliberação pública, mas procura entrar em sintonia, também, com o comportamento ulterior dos agentes que tomam parte na discussão.

Não é porque se constitui a vertente do pensamento democrático que parece dominar o debate corrente, contudo, que a proposta de democracia deliberativa encontra-se livre de críticas. As principais objeções referem-se à aplicabilidade e ao alcance dos pressupostos deliberativos em um cenário social tão plural, complexo e, logo, repleto de dificuldades - traços inegáveis do cotidiano das sociedades democráticas contemporâneas.

Sendo assim, não se poderia deixar de reconhecer as ressalvas mais candentes a apontarem falhas, por exemplo, quanto à engenharia deliberacionista cujo mote volta-se para a formulação de uma idéia de participação política dos cidadãos. A seção a seguir explora tais críticas.

\section{DAS CRÍTICAS À PERSPECTIVA DELIBE- RACIONISTA DE PARTICIPAÇÃO DA ESFERA CIVIL}

A reivindicação dos deliberacionistas, de terem formulado um modelo de democracia que demonstre consistência teórica e aplicabilidade

10 Luc Tremblay reforça essa concepção ao afirmar que participar é não apenas tomar parte no processo decisório, mas, também, ser responsável pelo que foi decidido (TREMBLAY, 2001). 
prática, é questionada por autores de distintas concepções concorrentes ao modelo discursivo (e até mesmo por autores internos a esse modelo), sendo o tema da participação civil um dos pontos mais polêmicos a caracterizar tal disputa.

Michael Walzer (1999), embora concorde com determinados diagnósticos elaborados pelo modelo deliberativo, tece algumas das críticas de maior relevância. Ele começa por apontar que a proposta discursiva de democracia não reconhece de modo adequado que o processo político possui valores para além do respeito recíproco, da capacidade de reflexão, da abertura e da generosidade por parte dos agentes envolvidos nos debates (sobretudo aqueles ligados às instituições democráticas). Em outras palavras, Walzer ressalta que a política é permeada por tensões (a exemplo da paixão e da crença em certas doutrinas, da coragem, da competitividade, da provocação, da barganha, da corrupção, dentre outros fatores) que vão de encontro à participação racional tão defendida nas sistematizações iniciais dos deliberacionistas.

Assim, nem sempre é possível praticar-se uma "economia da discordância moral" (como querem Gutmann e Thompson (1996)), argumenta Walzer. Não há como deixar de reconhecer que os indivíduos são volúveis, mudam de idéia e de sentimentos, lançam mão de estratégias duvidosas do ponto de vista ético para obter vitórias políticas, nem sempre agem de maneira racional ou mostram disposição em colaborar. Walzer afirma, então, que: "As paixões desbotam; homens e mulheres se desengajam de compromissos particulares; interesses de grupos tomam novas disposições; o mundo dá voltas. Mas certas discordâncias profundas, como aquela entre Direita e Esquerda, são notavelmente persistentes, e formas locais de conflitos étnicos e religiosos estão, muitas vezes, assim intrincadas em uma cultura política natural aos participantes. [...] enquanto a legitimidade é fortalecida se os bons argumentos podem ser feitos sobre os temas substantivos em questão, a vitória é raramente obtida pela construção de bons argumentos" (WALZER, 1999, p. 66-67).

Outro receio de Walzer refere-se ao fato de que a busca insistente por um ambiente cooperativo nos processos de discussão a envolverem temas de concernência pública pode levar a um distanciamento ou a uma desconsideração daquelas atividades que, essencialmente, nunca se voltaram para o alcance de concordâncias ou entendimentos. Imagine-se, por exemplo, a disputa pelo voto em debates acalorados levados à frente por adeptos de partidos colocados em lados opostos. Além de ser pouco provável um consenso, mesmo que parcial, acerca de como resolver certos problemas (uma vez que, em tais eventos, a meta não é deixar-se convencer, mas, primordialmente, vencer uma contenda), a busca pela cooperação poderia levar a uma diminuição do estímulo dos cidadãos em defender suas perspectivas ${ }^{11}$.

Por último, Walzer não nega que a deliberação tenha uma importância particular, mas dá a entender que ela funcionaria de modo mais adequado para as cortes judiciais do que para uma discussão ampla e inclusiva. Ao dizer que "a deliberação não é uma atividade para o demos", limitando, assim, a extensão da participação política em termos discursivos, o estudioso em tela duvida da capacidade deliberativa e cooperativa de um contingente de cidadãos numericamente representativo.

Outro crítico da proposta deliberativa de democracia, Ian Shapiro (1999; 2003), reforça a posição acerca da impraticabilidade da idéia de "economia da discordância moral" (GUTMANN \& THOMPSON, 1996). Isso porque o autor não acredita que, por exemplo, um fundamentalista religioso aceite, pacificamente, os princípios deliberativos de discussão propostos por

11 Wilson Gomes (2005) também critica a busca pelo entendimento e pela cooperação idealizada pelo modelo deliberativo. A ressalva de Gomes reside na consideração excessiva que Bohman oferece ao diálogo e ao comportamento cooperativo dos agentes em disputa no jogo político, o que acarreta uma desvalorização da importância e influência de atividades como a barganha, as negociações e demais conflitos típicos de um ambiente competitivo como o da política (GOMES, 2005). William Simon também se junta aos críticos realistas da deliberação quanto à possibilidade de alcançar-se o convencimento a partir do emprego do expediente discursivo. De acordo com esse autor: "Gutmann e Thompson não têm muito que dizer acerca das questões estratégicas na deliberação - na verdade, eles tendem a opor mentalidade estratégica à mentalidade deliberativa. [...] onde seu oponente toma uma posição por má fé, pode ser um equívoco deliberar. Ao 'tomar uma posição por má fé' eu quero dizer tanto se portar de modo conscientemente desonesto ou simplesmente não se estar aberto à reflexão" (SIMON, 1999 , p. 52-53). 
democratas como Gutmann e Thompson, exatamente porque muitos fundamentalistas não concordariam em abrir mão de determinadas crenças que caracterizam sua própria natureza. $\mathrm{O}$ argumento de Shapiro é delineado do seguinte modo: "Eu acho difícil imaginar um fundamentalista impressionado por isso, particularmente quando ele se dá conta de que qualquer reivindicação empírica que faça deve ser consistente com 'métodos de indagação relativamente confiáveis'. [...] O modelo de Gutmann e Thompson funciona apenas para aqueles fundamentalistas que também são democratas falíveis. Temo, eu, ser esta uma classe vazia e destinada a permanecer inabitada" (SHAPIRO, 1999, p. 30-31).

Ademais, a tentativa de aparar as arestas da discordância que a democracia deliberativa pretende fazer emergir pode, na verdade, possuir efeito contrário à intenção de compreender-se os motivos dos outros ${ }^{12}$. Nas palavras de Ian Shapiro: "Pode-se, razoavelmente, esperar que a deliberação enfatize a interação humana, mas isso pode acabar por revelar diferenças ocultas tanto trazer à tina possibilidades ocultas de convergência. Tudo depende de quais interesses essenciais estejam, de fato, em questão" (idem, p. 31-34).

Já Russell Hardin (1999) mostra-se incomodado com a imprecisão de determinadas propostas deliberativas. No intuito de demonstrar a pouca pertinência de um conjunto de aspectos do modelo em questão, sobretudo no que se refere à participação política dos cidadãos, Hardin pergunta-se, primeiramente: “Quem são os deliberantes? E quais são os temas acerca dos quais se supõe que eles deliberem? Se os cidadãos são os deliberantes e se as principais iniciativas públicas ou falhas de iniciativas residem nas questões, então, é difícil imaginar uma democracia deliberativa de relevância que não seja similar às visões dos defensores da democracia participativa" (idem, p. 114-115).

Hardin concorda com a premissa, tradicionalmente defendida por liberais como Schumpeter (1942) e Seymour Lipset (1981), de

12 Cass Sunstein (2002) identifica o risco de polarizações entre grupos uma vez que a deliberação esteja em curso, o que aponta para a necessidade de relativizarem-se os prospectos de cooperação e convergência apontado pelos autores do modelo discursivo (SUNSTEIN, 2002, 176-177). que a maioria dos cidadãos possui pouco interesse em participar, bem como não deseja estar a par dos acontecimentos políticos. Por isso, mesmo acreditando que a deliberação é uma peça importante, Hardin dá a entender que ela não pode ser expandida em proporções muito grandes a perigo de tornar-se ineficaz (HARDIN, 1999).

Assim, outra crítica refere-se à capacidade e à disposição dos cidadãos em tomarem parte nas arenas argumentativas. Álvaro de Vita (2004), ao corroborar algumas das idéias de autores ditos "realistas" (dentre esses, podemos mencionar Dahl (2001) e Mouffe (2005)), garante que apenas aqueles indivíduos já interessados tendem a integrar-se ao processo público de discussão, o que poderia fadar ao fracasso os princípios de modelos como o deliberacionismo e o participacionismo. Para esse autor, não se pode ignorar o deficit motivacional e cognitivo dos cidadãos referentes à participação em debates de natureza política. "A suposição de que os cidadãos devem deliberar sobre questões de política pública ignora o déficit motivacional e cognitivo desses cidadãos para lidar com questões dessa natureza. [...] O mais provável é que só estejam motivados a isso aqueles que têm preferências intensas sobre determinadas áreas da política pública [...]" (VITA, 2004, p. 115-117).

Vita observa, ainda, que a participação, tanto no deliberacionismo quanto no participacionismo, é vista mais como um fim em si mesmo do que como um elemento importante para obterem-se decisões de maior qualidade. Ou seja, ele questiona, ainda, a utilidade do envolvimento dos cidadãos nas discussões políticas.

A crítica de Álvaro de Vita parece ligada àquela de Lynn Sanders (1997), cujo texto, denominado Against Deliberation, um dos mais recorrentes a investir conta a noção de democracia deliberativa, alega que, não obstante a boa vontade dos deliberacionistas em tentar dar um novo fôlego à idéia de soberania popular, é necessário (a) reconhecer o declínio na disposição dos cidadãos em participar (seja por desilusão e cinismo, seja por falta de condições materiais) e (b) duvidar da boa vontade daqueles que dominam a cena política em dar ouvidos aos argumentos de novos agentes deliberantes. Ou seja, mais uma vez, questionase a aplicabilidade dos parâmetros propostos pelo modelo discursivo, sobretudo quando estão envolvidas as dimensões institucionais da política. 
Algumas dessas críticas foram reconhecidas pelos autores da vertente deliberativa, que não hesitaram em admitir os limites de certas propostas e concepções, mas que, ao mesmo tempo, procuraram refutar determinados argumentos de seus pares quanto à pouca plausibilidade prática e teórica atribuída ao modelo em questão. O tópico a seguir detalha como se dá a polêmica entre os deliberacionistas e seus críticos no que concerne à participação dos cidadãos e ressalta omissões importantes com as quais este modelo deve de lidar no intuito de se mostrar consistente em termos de teórica e prática política.

\section{O MODELO DELIBERATIVO E O RECO- NHECIMENTO DE SEUS LIMITES E AVAN- ÇOS}

Mais uma vez, insiste-se na necessidade de reconhecerem-se certas gradações testemunhadas em trabalhos de autores filiados à vertente discursiva (não se pretende, aqui, esgotar a revisão dessas diferentes concepções). No entanto, a premissa daqueles estudiosos deliberacionistas mais preocupados com a revitalização do conceito de soberania popular refere-se à noção de que os resultados das decisões políticas são legítimos apenas quando os cidadãos têm a chance de tomar parte no debate, oferecendo razões de caráter público e refletindo criticamente sobre cada um dos pontos polêmicos, na tentativa de encontrar convergências e negociar as divergências (HABERMAS, 1997). De acordo com John Dryzek (2004), entretanto, uma deliberação nesses termos dificilmente ocorreria em larga escala, reunindo milhões de cidadãos. Dryzek questiona, também, a viabilidade da participação nos moldes deliberativos na medida em que se constata certa indisposição da esfera civil em interferir nos negócios públicos. "[...] nas deliberações do mundo real, a totalidade como certamente a maioria dos afetados não parece participar, tornando desta forma a democracia deliberativa vulnerável ao destronamento de suas pretensões de legitimidade. [...] a teoria pende por um tenro fio se sua viabilidade depende crucialmente de uma vasta maioria que sempre opta por não exercer os direitos e capacidades que são tão fundamentais para a teoria [...]" (idem, p. 41-42).

Isso quer dizer que mesmo deliberacionistas a exemplo de John Dryzek reconhecem que nada pode dar a certeza de que os cidadãos, ainda que tenham à mão mecanismos e oportunidades de participação adequados, tomarão parte no processo político ou seguirão os parâmetros estabelecidos pelo modelo em tela neste trabalho ${ }^{13}$. Esse autor preocupa-se, ainda, em considerar a viabilidade de envolver-se um número tão extenso de participantes nas deliberações públicas, conforme crítica dos "realistas" quanto à concepção discursiva.

Em resposta a críticas como aquelas apontadas por Hardin (1999) e Vita (2004), no entanto, Dryzek esforça-se em desvincular a produção de decisões legítimas ao alcance de um número satisfatoriamente representativo de cidadãos. Ou seja, ele considera que "o número de participantes na deliberação é indeterminado", o que não implica restrição ou inclusão de mais ou menos agentes na discussão dos negócios públicos, contanto que a "constelação de discursos" possa receber contribuições de quaisquer das partes interessadas (DRYZEK, 2004, p. 54-55). O importante para Dryzek, nesses termos, não é a capacidade numérica de apoio que determinada proposta pode arregimentar, mas, sim, que a reflexão dentre aqueles envolvidos gere uma competição discursiva ampla ${ }^{14}$.

Outra crítica dentre as mais recorrentes ao modelo deliberativo refere-se ao fato de que essa concepção não leva em conta a complexidade e a pluralidade de perspectivas nas democracias contemporâneas (o que dificultaria o alcance de entendimentos). Assim, há teóricos que tomam como um ideal irrealizável a articulação entre complexidade social e organização democrática. James Bohman (1996), todavia, argumenta exatamente o contrário, ao sustentar que são os regimes democráticos aqueles que conseguem lidar de maneira mais adequada com a questão da complexidade, ao estabelecerem uma ordem mais flexível e aberta. As sociedades não democráticas,

\footnotetext{
13 Ver, também, Barabas (2004).

14 Na verdade, para Dryzek: “[...] participação e discussão extensas não são, necessariamente, úteis e podem, mesmo, exacerbar a complexidade e a paralisia na produção de políticas em vez de ajudar a lidar com elas" (DRYZEK, 1994, p. 70). Ressalte-se que, nos últimos anos, o autor vem desenvolvendo com maior profundidade a idéia de "representação discursiva" (DRYZEK \& NIEMEYER, 2008).
} 
continua o estudioso, tendem a dirimir os conflitos por meio da opressão, sem levar em conta diferentes ângulos acerca de um problema específico, com o objetivo de preservar sua estabilidade. Ora, mas não parece aceitável, diz Bohman, preservar tal estabilidade ao custo, por exemplo, da supressão de demandas diversas.

Uma vez que se tenha estabelecido e justificado a necessidade de acesso das diversas demandas (inclusive aquelas oriundas de atores da sociedade) ao processo de produção da decisão política para fortalecer-se o caráter da democracia, faz-se importante refletir, especificamente, acerca das críticas aos mecanismos de participação que a deliberação oferece para operar essas diferentes reivindicações. $\mathrm{Na}$ defesa por ele construída, Bohman reforça, primeiramente, o argumento de que é exatamente para diminuir o potencial dos conflitos políticos que a democracia deliberativa e seus princípios possuem um papel relevante. Em segundo lugar, o autor reconhece que não se deve contar com a expectativa de que a deliberação resulte em cooperação, principalmente porque nem todos aqueles envolvidos no processo discursivo precisam concordar com cada lei particular ou decisão (por outro lado, isso não implica necessidade de abrir mão da tentativa de diminuírem-se os focos de tensão trazidos pelas divergências.). O importante é, no final das contas, estabelecer termos de debate que permitam uma cooperação contínua em outras ocasiões (idem).

Isso significa, então, que os teóricos favoráveis à perspectiva da deliberação pública rejeitam como sua aquela idéia anteriormente a eles atribuída, de que o modelo apresenta como meta a busca por consensos. "Não é necessário, então, que cada um concorde com cada lei, objetivo ou decisão particular. Porém, mais é exigido dos cidadãos do que uma mera conformidade à lei” (idem, p. 183-184).

Já Gutmann e Thompson vão defender a proposta deliberativa de acusações relativas à persistência em intrometer-se nos mais diversos eventos da vida política das sociedades. Os autores dizem não reivindicar que toda e qualquer lei ou política pública sofra o mesmo tratamento deliberativo. Isso porque eles dizem reconhecer, por exemplo, dificuldades relativas ao tempo e à urgência com a qual devem ser tratadas determinadas decisões. Porém, mesmo que uma determinada política não tenha sido fruto de um processo inteiramente deliberativo, deve levar-se em conta o requisito fundamental de que os representantes precisam fazer-se responsabilizáveis em tempo integral, o que não invalida a exigência de sustentação discursiva (GUTMANN \& THOMPSON, 1999, p. 245-246).

Para além de outros problemas revelados à medida que se procura introduzir e elaborar mecanismos de participação deliberativa, o fato é que as críticas e as réplicas contribuem para aperfeiçoar, decisivamente, a proposta do modelo discursivo. Determinados posicionamentos apresentados em livros fundamentais para a concepção deliberacionista (BENHABIB, 1996; BOHMAN, 1996; GUTMANN \& THOMPSON, 1996) foram revisados e, juntamente com esclarecimentos adicionais, vão compondo uma compreensão de democracia que reúne contribuições de filósofos e de cientistas políticos.

\section{CONCLUSÕES}

Este trabalho procurou oferecer uma sistematização pouco recorrente nos estudos em teoria deliberativa, enfatizando aqueles requisitos e características que devem ser observados quando se procura compreender, em termos práticos e teóricos, o que o modelo discursivo entende como adequado do ponto de vista da participação política dos cidadãos.

Nem todos os investigadores deliberacionistas defendem com a mesma intensidade determinados aspectos atinentes à teoria e às práticas democráticas. Contudo, muito do que se refere à necessidade de promoção da participação política da esfera civil é visto, pelo menos em linhas gerais, com algum consenso. Pode-se dizer, assim, que os autores filiados à vertente aqui em questão defendem uma forma de participação que, não apenas em seu formato e desenvolvimento, mas, também, em suas conseqüências, respeite liberdades, direitos e opções individuais; tenha em mente espaços institucionais e efetivos de input, devendo tais inputs ser pautados pela discussão informada e por arrazoados cuja elaboração esteja subordinada a princípios de interação recíproca, publicidade e transparência; mantenha compromisso com a melhora nas condições sociais daqueles que tomam parte do processo político ou que são os alvos das políticas públicas. Não 
bastasse tal meta ambiciosa, os deliberacionistas apontam-se como formuladores de um modelo que, ao mesmo tempo, atende a requisitos de plausibilidade teórica e prática, o que engendra uma série de críticas (principalmente oriundas de autores ditos "realistas"), conforme apresentado.

Não há dúvidas de que o modelo deliberativo de democracia possui relevância não só ao representar um empreendimento recente em teoria democrática, mas, também, por fazer convergir concepções políticas aparentemente irreconciliáveis, como o liberalismo e o republicanismo.

Deve-se ressaltar, contudo, que a concepção deliberativa continua a omitir o tratamento de determinadas questões. No que se refere à participação política, especificamente, temas como o engajamento cívico e o capital social (enfatizados por Putnam (2000)) ou a importância da cultura política de cada sociedade são raramente examinados com a acurácia desejável.

Assim, além de especificar melhor a natureza da participação na deliberação pública (quem participa, no que participa, por qual motivo participa, como participa, que resultados essa participação traz, entre outras questões), há um conjunto de temas adicionais com os quais os deliberacionistas terão de lidar na intenção de oferecer uma proposta efetivamente viável de envolvimento dos cidadãos nas sociedades políticas contemporâneas.

Francisco Paulo Jamil Almeida Marques (marquesjamil@yahoo.com.br) é Doutor em Comunicação e Cultura Contemporâneas pela Universidade Federal da Bahia (UFBA) e Professor de Comunicação na Universidade Federal do Ceará (UFC).

\section{REFERÊNCIAS BIBLIOGRÁFICAS}

ABERS, R. 2000. Inventing Local Democracy: Grassroots Politics in Brazil. Boulder: L. Rienner.

ALMOND, G. \& VERBA, S. 1963. The Civic Culture: Political Attitudes and Democracy in Five Nations. Princeton: Princeton University.

ARATO, A. 2002. Representação, soberania popular, e accountability. Lua Nova, São Paulo, n. 55-56, p. 85-103. Disponível em: http:// www.scielo.br/pdf/ln/n55-56/a04n5556.pdf. Acesso em: 14.dez.2011.

ARNSTEIN, S. 1969. A Ladder of Citizen Participation. Journal of the American Planning Association, Chicago, v. 35, n. 4, p. 216-224, July. Disponível em: http:// www.historyofsocialwork.org/1969_ENG Ladderofparticipation/1969,\%20 Arnstein,\% 20ladder $\% 20$ of $\%$ 20participation, $\% 20$ original $\% 20$ text\%20OCR\%20C.pdf. Acesso em: 14.dez.2011.

AVRITZER, L. 2008. Instituições participativas e desenho institucional: algumas considerações sobre a variação da participação no Brasil democrático. Opinião Pública, Campinas, v. 14, n. 1, p. 43-64, jun. Disponível em: http:// www.scielo.br/pdf/op/v14n1/02.pdf. Acesso em: 12.dez.2011.

2009. Participatory Institutions in Democratic Brazil. Baltimore: John Hopkins University.

BARABAS, J. 2004. How Deliberation Affects Policy Opinions. American Political Science Review, Los Angeles, v. 98, n. 4, p. 687-701, Nov. Disponível em: http://economic education.us/dotAsset/1665571.pdf. Acesso em: 12.dez.2011.

BARBER, B. 2004. Strong Democracy: Participatory Politics for a New Age. Berkeley: University of California.

BENHABIB, S. 1996. Toward a Deliberative Model of Democratic Legitimacy. In: BENHABIB, S. (ed.). Democracy and Difference: Contesting the Boundaries of the Political. Princeton: Princeton University.

BENNETT, S. E. 1986. Apathy in America, 19601984: Causes and Consequences of Citizen Political Indifference. Ardsley: Transational.

BOBBIO, N. 2000. O futuro da democracia. $9^{\text {a }}$ ed. Rio de Janeiro: Paz e Terra. 
BOHMAN, J. 1996. Public Deliberation: Pluralism, Complexity and Democracy. Cambridge (MA): Massachussets Institute of Technology.

J. 1998. Survey Article: The Coming Age of Deliberative Democracy. The Journal of Political Philosophy, Hoboken, v. 6, n. 4, p. 400-425.

BURKHALTER, S.; GASTIL, J. \& KELSHAW, T. 2002. A Conceptual Definition and Theoretical Model of Public Deliberation in Small Face-to-Face Groups. Communication Theory, Washington (DC), v. 12, n. 4, p. 398422, Nov. Disponível em: http://www.la1. psu.edu/cas/jgastil/pdfs/Conceptual DefinitionDeliberation.pdf. Acesso em: 14.dez.2011.

CHAMBERS, S. 2003. Deliberative Democratic Theory. Annual Review of Political Science, Palo Alto, v. 6, p. 307-326, June.

COELHO, V. S. 2007. A democratização dos Conselhos de Saúde: o paradoxo de atrair não aliados. Novos Estudos, São Paulo, n. 78, p. 77-92, jul. Disponível em: http:// www.scielo.br/pdf/nec/n78/09.pdf. Acesso em: 14.dez.2011.

COHEN, J. 1996. Procedure and Substance in Deliberative Democracy. In: BENHABIB, S. (ed.). Democracy and Difference: Contesting the Boundaries of the Political. Princeton: Princeton University.

COHEN, J. \& ARATO, A. 1992. Civil Society and Political Theory. Cambridge (MA): Massachussets Institute of Technology.

COHEN, J. \& SABEL, C. 1997. DirectlyDeliberative Polyarchy. European Law Journal, Hoboken, v. 3, n. 4, p. 313-342, Dec.

CONOVER, P. J.; SEARING, D. D. \& CREWE, I. M. 2002. The Deliberative Potential of Political Discussion. British Journal of Political Science, Cambridge (UK), v. 32, n. 1, p. 21-62.

CONSTANT, B. 1985. Da liberdade dos antigos comparada à dos modernos. Revista de Filosofia Política, n. 2, p. 9-25. Disponível em: http://caosmose.net/candido/unisinos/ textos/benjamin.pdf. Acesso em: 14.dez.2011.
DAHL, R. 2001. Sobre a democracia. Brasília: UNB.

DELLI CARPINI, M. 2000. Gen.com: Youth, Civic Engagement, and the New Information Environment. Political Communication, London, v. 17, n. 4, p. 341-349. Disponível em: http://ccce.com.washington.edu/news/ assets/conference_papers/carpini.pdf. Acesso em: 14.dez.2011.

DRYZEK, J. S. 1994. Discursive Democracy: Politics, Policy, and Political Science. Cambridge (UK): Cambridge University.

2004. Legitimidade e economia na democracia deliberativa. In: COELHO, V. S. P. \& NOBRE, M. (orgs.). Participação e deliberação: teoria democrática e experiências institucionais no Brasil contemporâneo. São Paulo: ed. 34.

2007. Theory, Evidence, and the Tasks of Deliberation. In: ROSENBERG, S. (ed.). Deliberation, Participation and Democracy: Can the People Govern? Basingstoke: Palgrave.

DRYZEK, J. S. \& NIEMEYER, S. 2008. Discursive Representation. American Political Science Review, Los Angeles, v. 102, n. 4, p. 481-493, Nov. Disponível em: http:// www.democraciaparticipativa.org/bellagio/ arquivos/Dryzek-DISCREP\%20APSR08\% 20FINAL.pdf. Acesso em: 14.dez.2011.

DUTWIN, D. 2003. The Character of Deliberation: Equality, Argument, and the Formation of Public Opinion. International Journal of Public Opinion Research, Oxford, v. 15 , n. 3, p. 239-264.

ELIASOPH, N. 1998. Avoiding Politics: How Americans Produce Apathy in Everyday Life. Cambridge (UK): Cambridge University.

ELSTER, J. (ed.). 1998. Deliberative Democracy. New York: Cambridge University.

FISHKIN，J. S. 1991. Democracy and Deliberation: New Directions in Democratic Reform. New Haven: Yale University.

2002. Possibilidades democráticas virtuais: perspectivas da democracia via internet. In: EISENBERG, J. \& CEPIK, M. (orgs.). Internet e política: teoria e prática da democracia eletrônica. Belo Horizonte: UFMG. 
FRASER，N. \& HONNETH，A. 2003. Redistribution or Recognition? A PoliticalPhilosophical Exchange. London: Verso.

FUNG, A. 2005. Deliberation Before the Revolution: Toward an Ethics of Deliberative Democracy in an Unjust World. Political Theory, Thousand Oaks, v. 33, n. 3, p. 397-419, June. Disponível em: http://www.archonfung.net/papers/ FungDeliberationBefore.pdf. Acesso em: 14.dez.2011.

FUNG, A. \& WRIGHT, E. 2001. Deepening Democracy: Innovations in Empowered Participatory Governance. Politics \& Society, Thousand Oaks, v. 29, n. 1, p. 5-41, Mar. Disponível em: http://www.archonfung.net/ papers/FungDeepDemocPS.pdf. Acesso em: 14.dez.2011.

GASTIL，J. 2000. By Popular Demand: Revitalizing Representative Democracy Through Deliberative Elections. Berkeley: University of California.

GOMES, W. 2005. Da publicidade. s/1: s/n.

GUTMANN, A. \& THOMPSON, D. 1996. Democracy and Disagreement. Cambridge (MA): Harvard University.

1999. Disagreeing About Deliberative Democracy: Reply to the Critics. In: MACEDO, S. (ed.). Deliberative Politics: Essays on Democracy and Disagreement. New York: Oxford University.

2004. Why Deliberative Democracy? Princeton: Princeton University.

HABERMAS, J. 1997. Direito e democracia: entre faticidade e validade. Rio de Janeiro: Tempo Brasileiro.

HARDIN, R. 1999. Deliberation: Method, not Theory. In: MACEDO, S. (ed.). Deliberative Politics: Essays on Democracy and Disagreement. New York: Oxford University.

HELD, D. 1987. Models of Democracy. Stanford: Stanford University.

LIPSET, S. M. 1981. Political Man: The Social Bases of Politics. Baltimore: John Hopkins University.

MANIN, B. 1997. Principles of Representative Government. Cambridge (UK): Cambridge University.
MARQUES, F. P. J. A. 2008. Participação política e internet: meios e oportunidades digitais de participação civil na democracia contemporânea, com um estudo do caso brasileiro. Salvador. Tese (Doutorado em Comunicação e Cultura Contemporâneas). Universidade Federal da Bahia. Disponível em: http://www.ip.pbh.gov.br/ANO10 N2 PDF/ participacao_politica_internet.pdf. Acesso em: 14.dez.2011.

MOUFFE, C. 2005. Por um modelo agonístico de democracia. Revista de Sociologia e Política, Curitiba, n. 25, p. 11-23, nov. Disponível em: http://www.scielo.br/pdf/rsocp/n25/31108.pdf. Acesso em: 14.dez.2011.

MUHLBERGER, P. 2001. Social Capital and Deliberative Theory: A Synthesis and Empirical Test. Trabalho apresentado no Encontro Anual da American Political Science Association, San Francisco, ago.-set. Digit. Disponível em: www.geocities . com/p muh 178 / SocCapitalDeli.pdf. Acesso em: 14.dez.2011.

MUTZ, D. 2006. Hearing the Other Side: Deliberative versus Participatory Democracy. Cambridge (UK): Cambridge University.

NOBRE, M. 2004. Participação e deliberação na teoria democrática: uma introdução. In: COELHO, V. S. \& NOBRE, M. (orgs.). Participação e deliberação: teoria democrática e experiências institucionais no Brasil contemporâneo. São Paulo: ed. 34.

PATEMAN, C. 1992 Participação e teoria democrática. Rio de Janeiro: Paz e Terra.

PITKIN, H. 1987. The Concept of Representation. Berkeley: University of California.

PUTNAM, R. 2000. Bowling Alone: The Collapse and Revival of American Community. New York: Simon \& Schuster.

RAWLS, J. 1996. Political Liberalism. New York: Columbia University.

SANDERS, L. 1997. Against Deliberation. Political Theory, Thousand Oaks, v. 25, n. 3, p. 347-364, July. Disponível em: http:// faculty.virginia.edu/1sanders/SB617_01.pdf. Acesso em: 14.dez.2011.

SCHUMPETER, J. A. 1942. Capitalism, Socialism, and Democracy. New York: Harper and Brothers. 
SHAPIRO, I. 1999. Enough of Deliberation: Politics is about Interests and Power. In: MACEDO, S. (ed.). Deliberative Politics: Essays on Democracy and Disagreement. New York: Oxford University.

2003. The State of Democratic Theory. Princeton: Princeton University.

SILVA, F. C. 2004. Democracia deliberativa: avaliando os seus limites. Trabalho apresentado no $2^{\circ}$ Congresso da Associação Portuguesa de Ciência Política, Lisboa, jan. Disponível em http://www.ces.fe.uc.pt/ publicacoes/oficina/203/203.pdf. Acesso em 14.dez.2011.

SIMON, W. H. 1999. Three Limitations of Deliberative Democracy: Identity Politics, Bad Faith and Indeterminancy. In: MACEDO, S. (ed.). Deliberative Politics: Essays on Democracy and Disagreement. New York: Oxford University.

STEINER, J.; BÄCHTIGER, A. \& SPÖRNDLI, M. 2001. The Real World of Deliberation: Favourable Conditions and Substantive Outcomes. Trabalho apresentado na $1^{\text {a }}$ Conferência Geral do European Consortium for Political Research, Canterbury, set. Disponível em: http://www.ihrr.net/files/2006ss\% 20/Real-world-of-deliberation.pdf. Acesso em: 14.dez.2011.

SUNSTEIN, C. 2002. The Law of Group Polarization. Journal of Political Philosophy, Hoboken, v. 10, n. 2, p. 175-195, June.

TREMBLAY, L. 2001. Deliberative Democracy and Liberal Rights. Ratio Juris, Hoboken, v. 14, n. 4, p. 424-454, Dec.

URBINATI, N. 2006. Representative Democracy: Principles and Genealogy. Chicago: University of Chicago.
VERBA, S.; BRADY, H. \& SCHOLZMAN, K. 1995. Voice and Equality: Civic Volunteerism in American Politics. Cambridge (MA): Harvard University.

VITA, A. 2004. Democracia deliberativa ou igualdade eqüitativa de oportunidades? In: COELHO, V. S. \& NOBRE, M. (orgs.). Participação e deliberação: teoria democrática e experiências institucionais no Brasil contemporâneo. São Paulo: ed. 34.

VITALE, D. 2007. Representação política e participação: reflexões sobre o déficit democrático. Revista Katálysis, Florianópolis, v. 10, n. 2, p. 143-155, jul.-dez. Disponível em: http://www.scielo.br/pdf/rk/v10n2/ a02v10n2.pdf. Acesso em: 14.dez.2011.

WALZER, M. 1999. Deliberation... and What Else. In: MACEDO, S. (ed.). Deliberative Politics: Essays on Democracy and Disagreement. New York: Oxford University.

WAMPLER, B. \& AVRITZER, L. 2004. Participatory Publics: Civil Society and New Institutions in Democratic Brazil. Journal of Comparative Politics, New York, v. 36, n. 3, p. 291-312, Apr.

WARREN, M. 2007. Institutionalizing Deliberative Democracy. In: ROSENBERG, S. (ed.). Deliberation, Participation and Democracy: Can the People Govern? Basingstoke: Palgrave.

WEBER, M. 1946. Politics as a Vocation. In: GERTH, H. \& WRIGHT MILLS, C. From Max Weber: Essays in Sociology. New York: Oxford University.

YOUNG, I. M. 2000. Inclusion and Democracy. Oxford: Oxford University. 


\section{THE PROBLEM OF POLITICAL PARTICIPATION WITHIN THE DELIBERATIVE MODEL OF DEMOCRACY}

\section{Francisco Paulo Jamil Almeida Marques}

This paper discusses the premises of the deliberative model of democracy as they address the issue of political participation. We attempt to clarify what political participation means for those who use this model, while at the same time looking at some of the major critiques that have been directed toward it. Through a review of an important part of the literature, and without losing sight of earlier systematizations of democratic theory, three fundamental conditions for engendering participation according to this discursive model are pointed to: political institutions should create and offer citizens opportunities to participate in public input; improvement in people's socio-economic condition must be made; attention should be given to particular principles that have consistent regulatory influence on the interactions and arguments in question. This is followed by attention to the criticisms raised and flaws detected by deliberationism's detractors. At the end of the text, a summary of the strengths and weaknesses of the model is presented, along with a discussion of the problem of participation in contemporary democracies.

KEYWORDS: Participation; Deliberation; Democracy; Representation. 